08

\title{
Создание функциональных наноструктур под действием ионного облучения
}

\author{
(C) К.Е. Приходько, ${ }^{1,2}$ М.М. Дементьева ${ }^{1}$ \\ ${ }^{1}$ Национальный исследовательский центр „Курчатовский институт“, \\ 123182 Москва, Россия \\ ${ }^{2}$ Национальный исследовательский ядерный университет „МИФИ“, \\ 115409 Москва, Россия \\ e-mail: prihodko_ke@nrcki.ru
}

Поступило в Редакцию 8 мая 2021 г.

В окончательной редакции 8 мая 2021 г.

Принято к публикации 8 мая 2021 г.

Описан разработанный в НИЦ „Курчатовский институт“ метод создания различных функциональных наноструктур с использованием ионного облучения широким пучком. В качестве примера продемонстрировано формирование интегрированного сопротивления в нанопроводе, изготовленном из низкотемпературного сверхпроводника $\mathrm{NbN}$. Показана возможность изготовления при комнатной температуре изолирующего слоя оксида алюминия толщиной $15 \mathrm{~nm}$ на поверхности алюминия путем его облучения ионами кислорода с энергией $0.2 \mathrm{keV}$.

Ключевые слова: ионное облучение, тонкие сверхпроводящие пленки $\mathrm{NbN}$, интегрированные криогенные резисторы, создание изолирующих слоев под облучением.

DOI: 10.21883/JTF.2021.10.51367.138-21

\section{Введение}

В настоящей работе использованы разрабатываемые в НИЦ „Курчатовский институт“ методы направленной модификации свойств тонкопленочных материалов под действием ионного облучения, позволяющие преобразовывать атомный состав и свойства материалов для придания требуемых функциональных характеристик. В качестве параметров выступают: энергия и тип используемых частиц, флюенс, состав ионного пучка, температура подложки в процессе облучения.

Среди разработанных экспериментальных методов можно выделить: способ преобразования диэлектриков в металлы [1], металлов и полупроводников в диэлектрики [2], немагнитных материалов в магнитные [3], изменения оптического показателя преломления, преобразования сверхпроводников в металлы [4] и диэлектрики [5] и т. п. под действием ионного облучения.

Для формирования требуемой топологии наноструктур необходимо сформировать защитную маску для того, чтобы выделить области для проведения облучения. Маска создается зондовыми методами с применением сфокусированного электронного пучка или сфокусированного ионного пучка.

После формирования защитной маски преобразование свойств при формировании наноструктуры осуществляется широким ионным пучком различного состава на любом ионном источнике (плазменный генератор, ускоритель и т.п.), что может быть использовано для большого количества приложений.

Были продемонстрированы созданные различные функциональные наноразмерные устройства и функци- ональные элементы: нанопроводники в матрице диэлектрика [6], высокоплотные паттернированные магнитные среды [3], наноразмерные логические элементы на основе низкотемпературных сверхпроводников [7].

\section{1. Методика эксперимента}

Функциональные тонкие пленки, из которых изготавливаются наноструктуры, наносятся на подложку методами напыления (катодное, магнетронное, лазерное распыление и т.п.). В настоящей работе тонкие пленки из низкотемпературного сверхпроводящего нитрида ниобия были изготовлены методом катодного распыления при температуре подложки $800^{\circ} \mathrm{C}$ [8]. Пленки металлического алюминия толщиной $\sim 50 \mathrm{~nm}$ были получены при комнатной температуре методом катодного распыления [9] на подложках из монокристаллического кремния.

На поверхности пленки формировалась защитная маска из позитивного электронного резиста ПММА, в которой методом электронной литографии создавались окна для проведения ионного облучения. Формирование нанопроводов из сплошной пленки $\mathrm{NbN}$ также проводилось посредством электронной литографии и последующего реактивного травления.

Преобразование тонкопленочного нитрида ниобия выполнялось под действием смешанного ионного облучения с использованием широкого пучка протонов и ионов $\left(\mathrm{OH}^{+}\right)$остава $c=1.2 \cdot 10^{-3}[2]$. В данной работе преобразование тонкопленочного нитрида ниобия в фазу [10], проявляющую металлические свойства при температуpe $4.2 \mathrm{~K}$, проводилось под действием смешанного ионно- 
- Metal atoms

- Nitrogen atoms

- Oxygen ions $\left(\mathrm{O}^{+}\right)$

- Protons $\left(\mathrm{H}^{+}\right)$

Metal nitride initial film
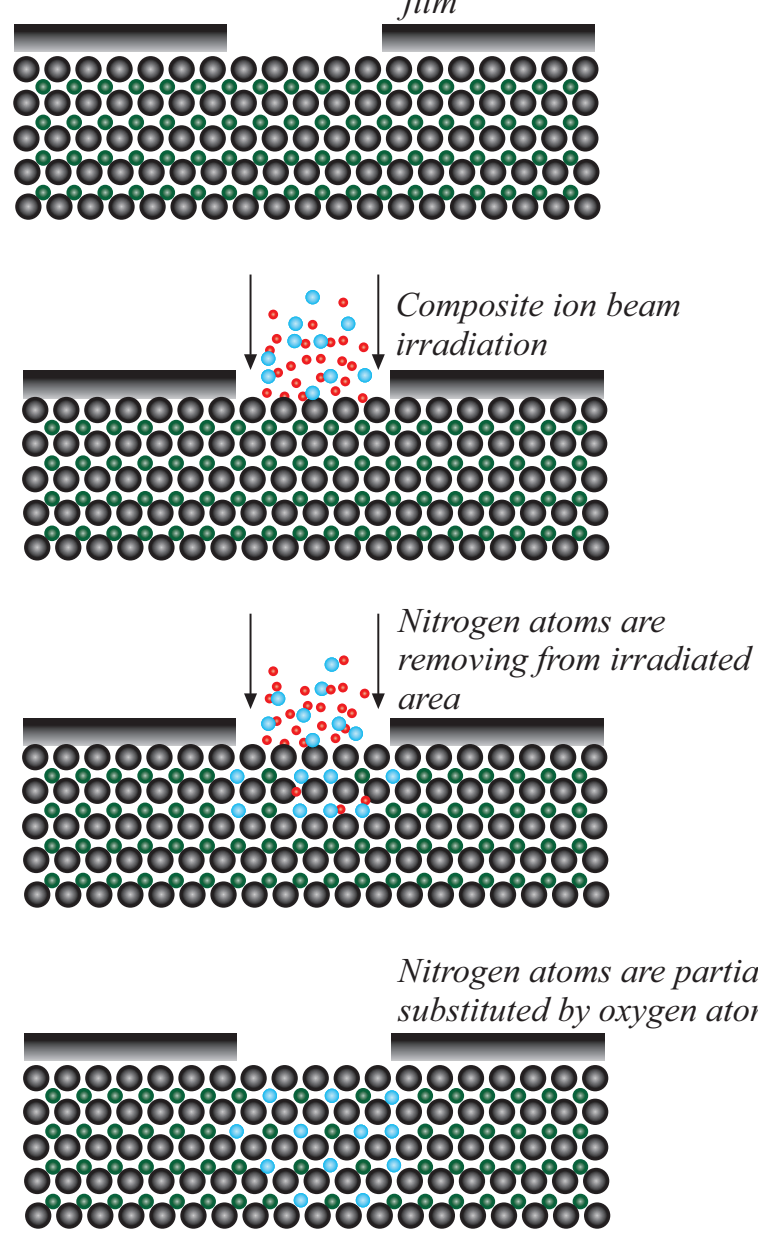

- Metal atoms

$b$

- Oxygen ions $\left(\mathrm{O}^{+}\right)$

- Protons $\left(\mathrm{H}^{+}\right)$
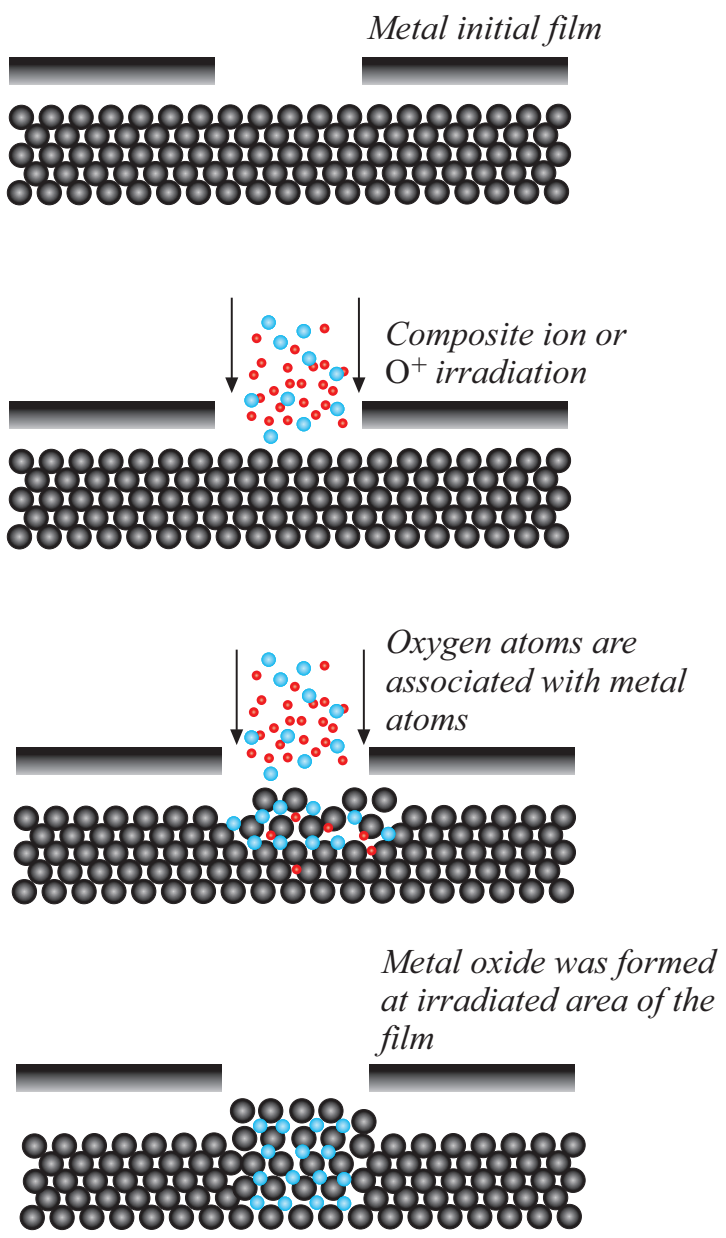

Рис. 1. Схема протекания процессов селективного изменения атомного состава: $a$ - замещения атомов азота на атомы кислорода при облучении тонкопленочного нитрида ниобия через маску смешанным пучком, состоящим из протонов и ионов кислорода; $b-$ соединения атомов в процессе облучения материала мишени смешанным ионным пучком или ионами кислорода.

го облучения до дозы $\sim 1 \mathrm{dpa} \mathrm{по} \mathrm{азоту} \mathrm{[4].} \mathrm{Радиационно-}$ индуцированное окисление алюминия выполнялось при комнатной температуре образца под действием облучения ионами кислорода с энергией $0.2 \mathrm{keV}$.

Образцы поперечных срезов для проведения микроструктурных исследований изготавливались методом сфокусированного ионного пучка (ФИП) на установке „Helios Nanolab 650“ (FEI) при энергии ионов Ga на этапе предварительной вырезки $30 \mathrm{keV}$, на этапе окончательной полировки $-2 \mathrm{keV}$.

Определение распределения атомных концентраций химических элементов проводилось методом относительных концентраций путем анализа спектров энергетических потерь энергии электронов (EELS) [11] в рамках просвечивающей растровой электронной микроскопии (ПРЭМ) с использованием просвечивающего электронного микроскопа „Titan 80-300 ST“ (FEI), осна- щенного спектрометром „GIF-2001“ (Gatan) при энергии электронов $200 \mathrm{keV}$.

\section{2. Результаты и обсуждение}

В настоящей работе в качестве примера применения методов направленной модификации атомного состава тонкопленочных материалов под действием ионного облучения для создания наноструктур рассмотрен процесс формирования интегрированного сопротивления малого номинала $(\sim 50 \Omega)$ в нанопроводах из сверхпроводящего $\mathrm{NbN}$. Интегрированные сопротивления используются при конструировании схем для криогенных логических элементов.

На рис. 1, а представлена схема протекания процесса селективного замещения атомов [2] при воздействии 
смешанного ионного облучения на нитрид ниобия. Тонкопленочный нитрид ниобия подвергается облучению через маску смешанным ионным пучком, в результате чего при определенных дозах облучения атомы азота частично удаляются из материала мишени, замещаясь на атомы кислорода. Как было показано ранее, в результате облучения пленки нитрида ниобия смешанным ионным пучком, состоящим из протонов и ионов кислорода (или ионов $\mathrm{OH}^{+}$) до доз $(1-2) \mathrm{dpa}$ по азоту, происходит частичное замещение атомов азота атомами кислорода, что инициирует образование кристаллической фазы оксинитрида ниобия [10], проявляющего металлические свойства при температуре $4.2 \mathrm{~K}$ [4]. Преобразование состава и свойств сверхпроводящего нитрида ниобия производилось путем облучения через маску, сформированную из электронного резиста методами электронной литографии. В настоящей работе в качестве материала маски был использован электронный позитивный резист ПММА.

На рис. 2,b показан сверхпроводящий нанопровод, сформированный из сплошной пленки нитрида ниобия методом электронной литографии и последующего ионно-реактивного травления, ширина которого составляет $350 \mathrm{~nm}$. В средней части ширина изменяется, достигая величины $6400 \mathrm{~nm}$, что сделано для изготовления интегрированного сопротивления с малым номиналом. Большая ширина нанопровода в месте создания сопротивления с малым номиналом необходима для формирования малого числа квадратов в области проведения облучения, где формируется нормальный металл из сверхпроводника.

На рис. 2, $b$ показана щелевая маска для проведения ионного облучения. Данная комбинация малой ширины щели в маске и большой ширины нанопровода в месте формирования сопротивления позволяет создать малый номинал интегрированного сопротивления $60 \Omega$ (см. вольт-амперную характеристику на рис. $2, c$ ).

На рис. 3 представлено ПЭМ изображение высокого разрешения материала пленки после облучения смешанным ионным пучком до флюенса $\sim 1$ dра по азоту, полученное на образце поперечного среза открытой области нанопровода после облучения, изготовленном методом сфокусированного ионного пучка (ФИП). Как показала расшифровка атомной структуры зерен на рис. 3, в результате протекания процесса селективного замещения атомов под действием облучения часть атомов азота была замещена атомами кислорода, в результате чего был сформирован оксинитрид ниобия, проявляющий металлические свойства при температуре $4.2 \mathrm{~K}$.

Еще одним применением методов направленной модификации тонких слоев материалов под действием ионного облучения является использование технологии селективного атомного соединения (САС), схема которой представлена на рис. $1, b$ : тонкая металлическая пленка подвергается облучению через маску смешанным ионным пучком, в результате чего атомы кислорода

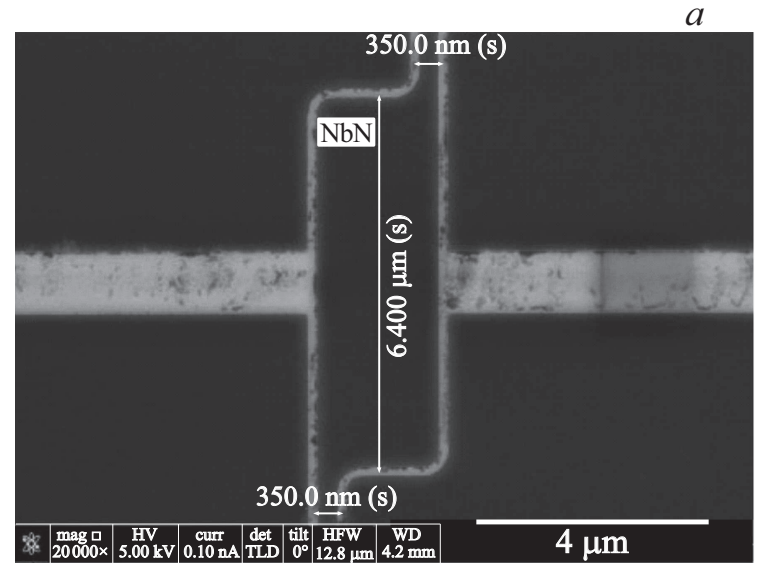

$b$
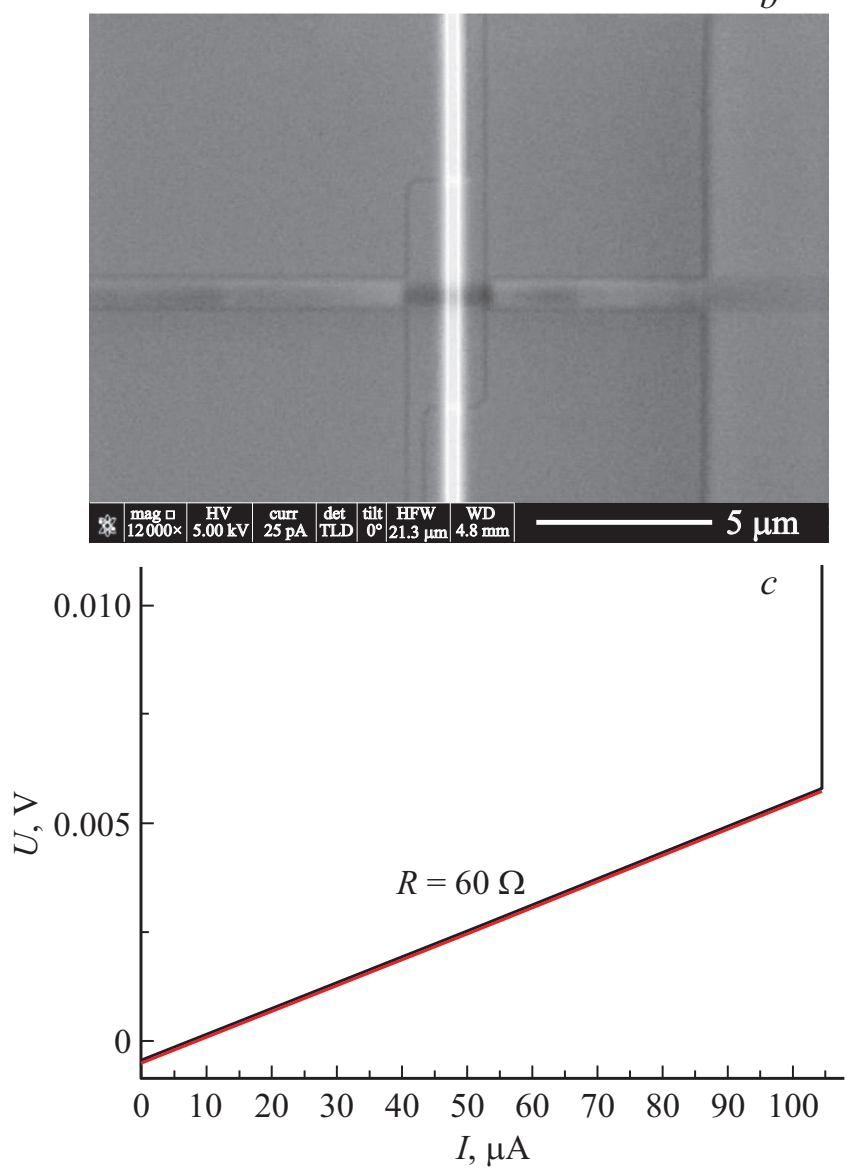

Рис. 2. $a-$ сверхпроводящий нанопровод, сформированный из сплошной пленки из $\mathrm{NbN}$ методом реактивного ионного травления через маску из ПММА, структурированную методом электронной литографии; $b-$ маска из ПММА с сформированной щелью для проведения облучения при создании сопротивления; $c-$ зависимость электрического напряжения на нанопроводе от тока через него.

внедряются в материал мишени на глубину проективного пробега легкой составляющей ионного пучка (протонов), образуя оксид металла. Таким образом, при облучении материалов ионными пучками смешанного состава (протонов и ионов кислорода) или моносостава 


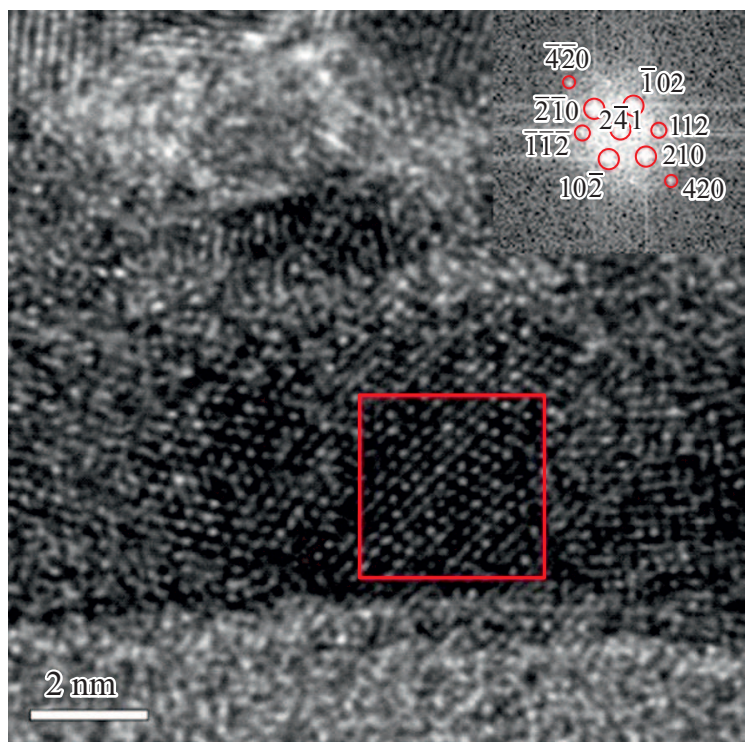

Рис. 3. ПЭМ изображение атомной структуры материала сопротивления после модификации под действием облучения (NbNO). Вставка - картина преобразования Фурье.

(ионов кислорода), тонкий поверхностный слой мишени окисляется. Радиационные дефекты, образующиеся в материале в ходе ионного облучения, предоставляют пространство для образования оксида, который занимает больший удельный объем по сравнению с исходным металлом, а атомы кислорода либо напрямую имплантируются в материал с энергией падающего пучка (облучение ионами кислорода), либо диффундируют из зоны имплантации по дефектам, созданным более легкой компонентой ионного пучка (в случае использования смешанного ионного пучка - протонами). Отличия в случае облучения моноионным или смешанным ионным пучками заключаются в скорости окисления, а также в глубине зоны окисления. Как было показано ранее на примере радиационно-индуцированного окисления кремния [2], глубина окисления определяется величиной полного проективного пробега ионов кислорода в материале мишени (для случая кислородного пучка) или величиной полного проективного пробега протонов (для случая смешанного облучения).

В настоящей работе проводилось радиационноиндуцированное окисление металлического алюминия под действием облучения ионами кислорода с энергией $0.2 \mathrm{keV}$ до дозы $1.3 \cdot 10^{18} \mathrm{~cm}^{-2}$. Облучение ионами кислорода с энергией $0.2 \mathrm{keV}$ позволяет, с одной стороны, избежать значимого эффекта распыления атомов поверхности в процессе окисления, а с другой - осуществить окисление на значимую глубину, чтобы обеспечить электрическую изоляцию за счет формирования качественного диэлектрика.

Для изучения свойств диэлектрика, сформированного под действием облучения металлического алюминия ионами кислорода с энергией $0.2 \mathrm{keV}$, в настоящей ра- боте были выполнены микроструктурные исследования поперечных срезов облученных образцов методом спектроскопии энергетических потерь энергии электронов с применением просвечивающей растровой электронной микроскопии (ПРЭМ). Образцы поперечных срезов были изготовлены методом сфокусированного ионного пучка (ФИП). На рис. 4 показаны распределения атомных концентраций алюминия и кислорода по глубине облученного образца. Как видно из рис. 4, глубина окисления при данной дозе облучения составляет $\sim 15 \mathrm{~nm}$, при этом соотношение атомных концентраций элементов соответствует предельному оксиду алюминия $\mathrm{Al}_{2} \mathrm{O}_{3}$.

Кроме изучения распределения элементов по глубине мишени, в настоящей работе были выполнены измерения электрических свойств образованной пленки оксида алюминия. Для этой цели были проведены измерения вольт-амперных характеристик в вертикальной геометрии (рис. 5,a). Поскольку толщина пленки радиационно-индуцированного оксида 3 меньше, чем толщина исходного слоя алюминия, оставшийся неокисленный слой алюминия был использован в качестве нижнего контакта 2 при измерении тока в вертикальной геометрии. В качестве верхней измерительной площадки был использован слой напыленной на ФИП площадки из платины размером $20 \times 20 \mu \mathrm{m}^{2} 4$ (также рис. $5, b$ ).

Электрические измерения проводились четырехзондовым методом для надежной регистрации сигнала при малых измерительных токах и исключения влияния контактных сопротивлений. При проведении таких измерений большие величины электрических сопротивлений накладывают ограничения на возможные измерительные токи, поскольку возникающая на вертикальной структуре разность потенциалов не должна превышать величину пробойного напряжения диэлектрика. Как видно из вольт-амперной характеристики на рис. 5, $c$, при максимальном измерительном токе $300 \mathrm{fA}$ напряжение на структуре достигает $100 \mathrm{mV}$, т.е. напряженность

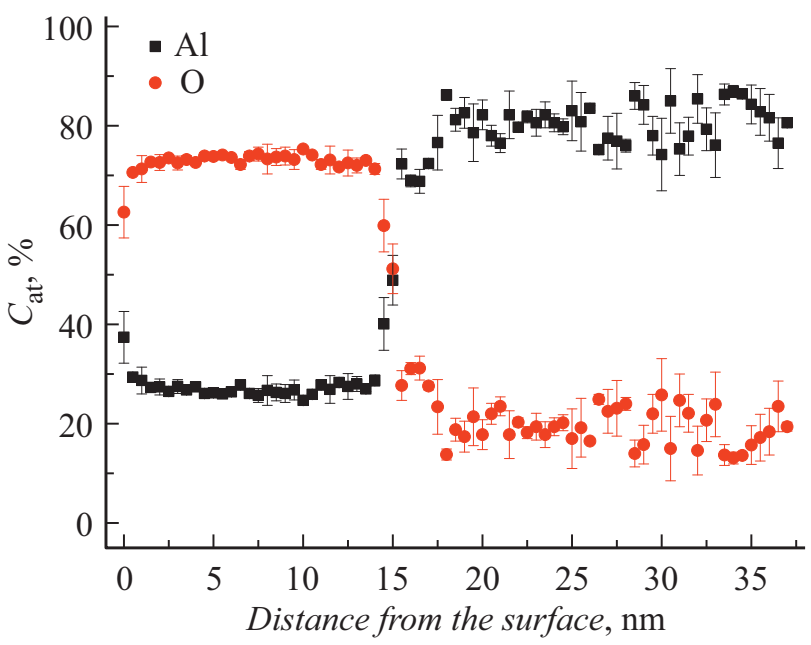

Рис. 4. Профили распределения элементов $(\mathrm{Al}, \mathrm{O})$ по глубине пленки алюминия, облученной ионами кислорода с энергией $0.2 \mathrm{keV}$ до дозы $1.3 \cdot 10^{18} \mathrm{~cm}^{-2}$. 


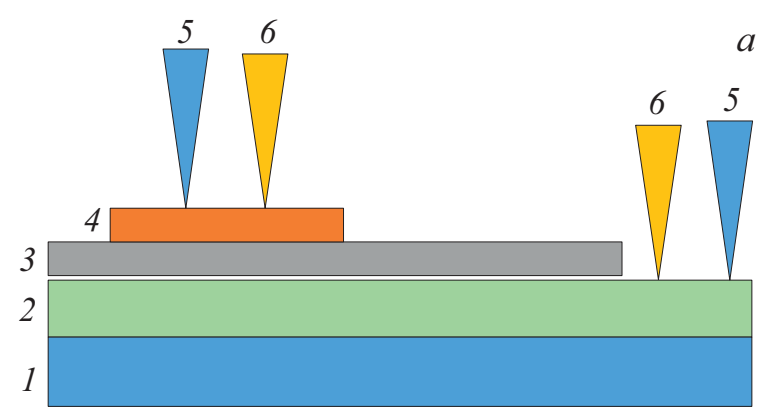

$b$
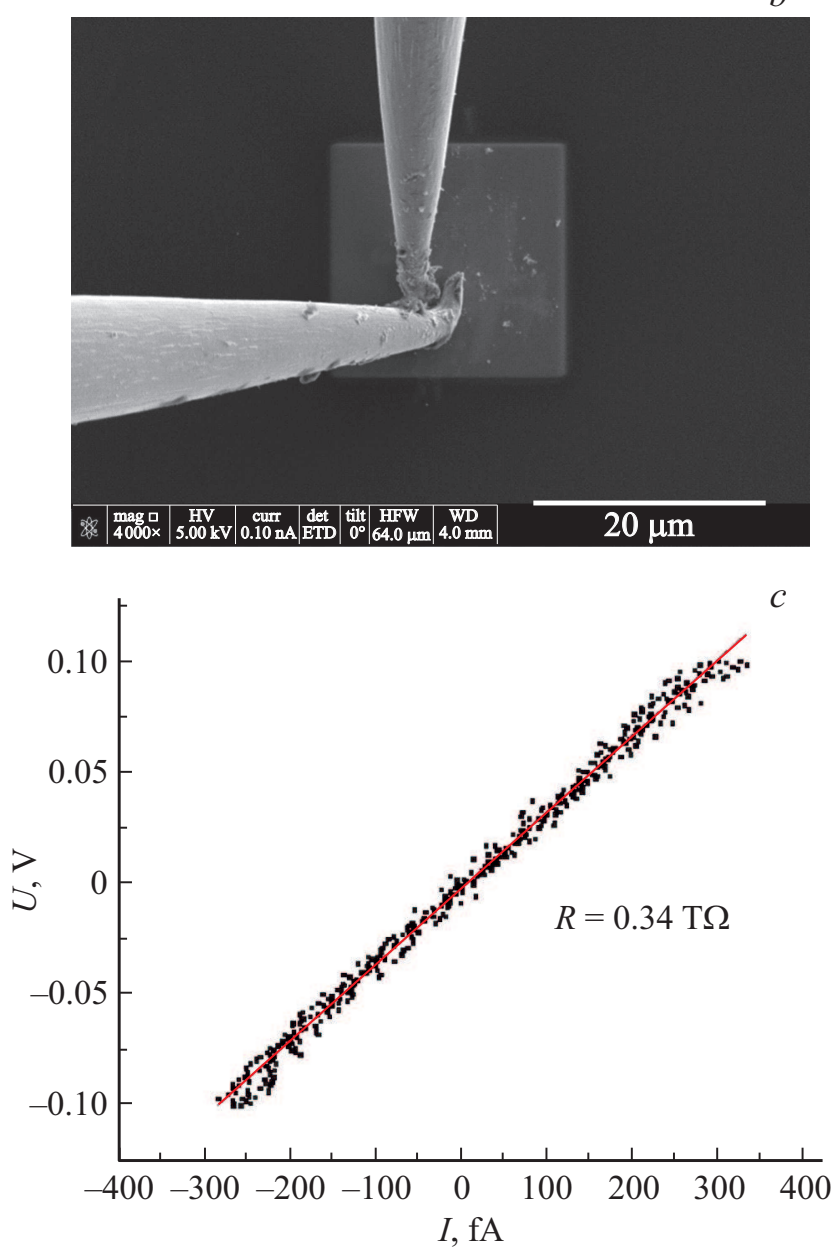

Рис. 5. $a-$ схема проведения измерений электрических свойств сформированного оксида: 1 - подложка, $2-$ напыленный алюминий, 3 - оксид алюминия, сформированный под действием облучения, $4-$ верхний контакт из платины, напыленный с помощью ФИП, 5 - токовые зонды, 6 потенциальные зонды для проведения четырехточечных измерений; $b-$ РЭМ изображение верхней контактной площадки с измерительными зондами; $c-$ вольт-амперная характеристика созданного оксида алюминия, измеренная в вертикальной геометрии четырехзондовым методом.

электрического поля $66 \mathrm{kV} / \mathrm{cm}$ несколько ниже пробойной напряженности ( $250 \mathrm{kV} / \mathrm{cm})$. По наклону кривой на рис. 5,c было определено значение электрического сопротивления структуры в вертикальной геометрии
$(0.34 \mathrm{~T} \Omega)$, что соответствует удельному электрическому сопротивлению $\sim 10^{10} \Omega \cdot \mathrm{m}$, превышающему значения удельного сопротивления пленок оксида алюминия, полученных традиционными методами анодирования в щелочных $\left(\sim 10^{8} \Omega \cdot \mathrm{mm}\right)$ и в кислотных растворах $\left(10^{7}-10^{13} \Omega \cdot \mathrm{mm}\right)[12]$.

\section{Выводы}

В работе продемонстрирован метод селективного атомного замещения на примере формирования интегрированного сопротивления малого номинала из сверхпроводящего нитрида ниобия, облученного смешанным ионным пучком через маску. Геометрия окна в маске обеспечивает правильную величину номинала сопротивления. Также продемонстрировано использование метода селективного атомного соединения на примере создания диэлектрического слоя на поверхности проводника путем облучения металлического алюминия ионами кислорода при комнатной температуре. Проведены измерения электрических характеристик созданного оксида алюминия и получены высокие диэлектрические свойства $\left(\rho \sim 10^{10} \Omega \cdot \mathrm{m}\right)$. Метод облучения материалов через маску заданной геометрии позволят формировать различные функциональные элементы (металлические, магнитные, оптические и др.), в том числе нанометровых размеров.

\section{Благодарности}

Авторы выражают благодарность В.Л. Столярову, Е.Д. Ольшанскому, В.Н. Мисько, Д.А. Гончаровой, Е.М. Малиевой за изготовление тонких пленок нитрида ниобия и наноструктур, Д.А. Комарову за проведение ионного облучения, а также Л.В. Кутузову и Б.В. Гончарову за проведение электрических измерений.

\section{Финансирование работы}

Работа выполнена при поддержке Национального исследовательского центра „Курчатовский институт“ (приказ от 02.07.2020 № 1055).

\section{Конфликт интересов}

Авторы заявляют, что у них нет конфликта интересов.

\section{Список литературы}

[1] Б.А. Гурович, К.Е. Приходько. УФН, 179 (2), 179 (2009). DOI: $10.3367 /$ UFNr.0179.200902d.0179 [B.A. Gurovich, K.E. Prikhod'ko. Physics-Uspekhi, 52 (2), 165 (2009). DOI: $10.3367 /$ UFNe.0179.200902d.0179]

[2] Б.А. Гурович, К.Е. Приходько, Е.А. Кулешова, К.И. Маслаков, Д.А. Комаров. ЖЭТФ, 143 (6), 1062 (2013). DOI: $10.7868 / \mathrm{S} 0044451013060062$ 
[3] B.A. Gurovich, K.E. Prikhodko, E.A. Kuleshova, A.Yu. Yakubovsky, E.Z. Meilikhov, M.G. Mosthenko. J. Magn. Magn. Mater., 322 (20), 3060 (2010).

DOI: $10.1016 /$ j.jmmm.2010.05.029

[4] B.A. Gurovich, K.E. Prikhodko, M.A. Tarkhov, A.G. Domantovsky, D.A. Komarov, B.V. Goncharov, E.A. Kuleshova. Micro Nanosyst., 7 (3), 172 (2015). DOI: $10.2174 / 1876402908666151228233002$

[5] Б.А. Гурович, К.Е. Приходько, М.А. Тархов, Е.А. Кулешова, Д.А. Комаров, В.Л. Столяров, Е.Д. Ольшанский, Б.В. Гончаров, Д.А. Гончарова, Л.В. Кутузов, А.Г. Домантовский, 3.В. Лаврухина, M.M. Дементьева. Российские нанотехнологии, 10 (5-6), 25 (2015). [B.A. Gurovich, K.E. Prikhod'ko, M.A. Tarkhov, E.A. Kuleshova, D.A. Komarov, V.L. Stolyarov, E.D. Ol'shansky, B.V. Goncharov, D.A. Goncharova, L.V. Kutuzov, A.G. Domantovskii, Z.V. Lavrukhina, M.M. Dement'eva. Nanotechnologies in Russia, 10 (7-8), 530 (2015). DOI: 10.1134/S1995078015040072]

[6] Б.А. Гурович, К.Е. Приходько, А.Н. Талденков, А.Г. Домантовский, Д.А. Комаров, Л.В. Кутузов. Российские нанотехнологии, $7(1-2), 41$ (2012). [В.А. Gurovich, K.E. Prikhod'ko, A.N. Taldenkov, A.G. Domantovskii, D.A. Komarov. Nanotechnologies in Russia, 7 (1-2), 28 (2012). DOI: 10.1134/S1995078012010089]

[7] Б.А. Гурович, К.Е. Приходько, Л.В. Кутузов, Б.В. Гончаров. ФТТ, $\mathbf{6 2}(9), \quad 1420 \quad$ (2020). DOI: $10.21883 / \mathrm{ftt} .2020 .09 .49764 .23 \mathrm{~h}$ [B.A. Gurovich, K.E. Prikhod'ko, L.V. Kutuzov, B.V. Goncharov. Phys. Solid State, 62, 1585 (2020). DOI: 10.1134/S1063783420090103]

[8] Б.А. Гурович, М.А. Тархов, К.Е. Приходько, Е.А. Кулешова, Д.А. Комаров, В.Л. Столяров, Е.Д. Ольшанский, Б.В. Гончаров, Д.А. Гончаров, Л.В. Кутузов, А.Г. Домантовский. Российские нанотехнологии, 9(7-8), 36 (2014). [B.А. Gurovich, M.A. Tarkhov, K.E. Prikhod'ko, E.A. Kuleshova, D.A. Komarov, V.L. Stolyarov, E.D. Ol'shansky, B.V. Goncharov, D.A. Goncharova, L.V. Kutuzov, A.G. Domantovskii. Nanotechnologies in Russia, 9(7-8), 386 (2014). DOI: 10.1134/S1995078014040077]

[9] Д.И. Долгий, Е.Д. Ольшанский, Е.П. Рязанцев. Конверсия в машиностроении, 3-4, 119 (1999).

[10] K.E. Prikhodko, B.A. Gurovich, M.M. Dement'eva. IOP Conf. Ser. Mater. Sci. Eng., $130(1), 012058$ (2016). DOI: $10.1088 / 1757-899 X / 130 / 1 / 012058$

[11] М.М. Дементьева, К.Е. Приходько, Б.А. Гурович, Л.В. Кутузов, Д.А. Комаров. ФТТ, 58 (11), 2104 (2016). DOI: $10.21883 / \mathrm{ftt} .2016 .11 .43720 .5 \mathrm{k}$. [M.M. Dement'eva, K.E. Prikhod'ko, B.A. Gurovich, L.V. Kutuzov, D.A. Komarov. Physics Solid State, 58(11), 2177 (2016). DOI: $10.1134 / \mathrm{S} 1063783416110068]$

[12] М.М. Филяк, О.Н. Каныгина. Вестник ОГУ, 9 (158), 240 (2013). 